\title{
RACE COMPOSITION AND DISTRIBUTION OF BROOMRAPE (Orobanche cumana Wallr.) IN BULGARIA DURING 2007 - 2011
}

\author{
Shindrova, P. ${ }^{*}$ and Penchev, E.
}

Dobroudja Agricultural Institute - General Toshevo, Bulgaria

Received: September 29, 2012 Accepted: December 10, 2012

SUMMARY

In order to determine the race composition and distribution of broomrape in Bulgaria during the period 2007 - 2011, samples (seeds) of the parasite were collected in 116 different locations from the main sunflower production regions. The collected seeds were used to infect differential sets of genotypes by a standard methodology.

According to the results obtained from this investigation, the broomrape population in Bulgaria includes 4 races: $\mathrm{E}, \mathrm{F}, \mathrm{G}$ and $\mathrm{H}$. Races $\mathrm{E}$ and $\mathrm{G}$ were most widely distributed. During the years of investigation race $\mathrm{E}$ gradually decreased its percentage in the population but was still predominant in the region of north-east Bulgaria while becoming almost equal with race $G$ in the region of central north Bulgaria. In south-east Bulgaria, the population included only race $\mathrm{G}$, which will probably increase its percentage in other regions as well in the upcoming years. Race $\mathrm{F}$ was of sporadic occurrence. It was isolated in single years, its distribution was limited and there is no danger of its mass occurrence. The population identified as race $\mathrm{H}$ was isolated only in 2007. This population may be considered a "primary" source of infection that will be expanding from now on; for the time being, however, it is localized on a very small area.

\section{Key words: broomrape, race composition, distribution}

\section{INTRODUCTION}

Broomrape occurred in Bulgaria with the very introduction of sunflower as a field crop. The first attacks on sunflower crops have been reported in 1935 (Dobrev, 1945). At the beginning broomrape was distributed in the region of northeast Bulgaria, mainly in the border area with Romania and along the north Black sea coast. The new races of the parasites originated from this region (Encheva, Shindrova, 1994).

* Corresponding author: 
Control of broomrape in Bulgaria is done mainly by the introduction and growing of resistant varieties and hybrids. This practice has led to the disappearance of the "old" races, and the strong breeding pressure stimulated the parasite to form new, more virulent races. After 1995 a new broomrape race was identified - race E. Soon the population of the parasite plant was enriched with another two races: race F in 2003 (Shindrova, 2006) and race G in 2006 - 2007. This fact has its logical explanation: during the recent years varieties and hybrids resistant to the parasite were registered and grown in Bulgaria.

Besides the occurrence of new races, the parasite is expanding its areas of distribution in the recent years mainly due to the changes in the system of agriculture, including sunflower production:

- The areas sown with sunflower have increased many times: from 2,500,000 da till 1990 to approximately 6,500,000 da in 2010 - 2011. This has caused a systematic disturbance of proper crop rotation. Sunflower is grown in practice on the same field for two or three years at the most.

- There is little control on the import of sunflower seeds from hybrids with unknown origin and susceptibility to broomrape.

- Seed production of lines and hybrids without resistance to the parasite was allowed.

- Main phyto-sanitary and agronomy practices are not observed, such as crop rotation, spatial isolation, disease and pest control, weed control, deep soil tillage, etc.

As a result the parasite has expanded to new regions and the percentage and rate of attack in the old regions has increased.

The aim of this investigation was to determine the race variability of the parasite and the areas of distribution of the individual races during $2007-2011$. The obtained results will provide useful information for both the needs of breeding and for practical purposes when distributing the varieties and hybrids.

\section{MATERIAL AND METHODS}

The results from our previous studies showed that the broomrape population in Bulgaria does not include races A, B and C of the parasite (Shindrova, 2006). Therefore, we used differential set of genotypes to identify only races D, E, F, G and $\mathrm{H}$ (Table 1).

Table 1: Differential set for identification of broomrape races (Orobanche cumana Wallr.)

\begin{tabular}{lcccc}
\hline Races* & \multicolumn{4}{c}{ Differential set: } \\
\cline { 2 - 5 } & Iso & Super-25 & Jara & Tunca \\
\hline D & R & R & R & R \\
E & S & R & R & R \\
F & S & S & R & R \\
G & S & S & S & R \\
H & S & S & S & S \\
\hline
\end{tabular}


The term "race" as used in this study means the parasite population originating from different fields.

Table 2: Number of samples analyzed during 2007 - 2011

\begin{tabular}{lcccc}
\hline \multirow{2}{*}{ Year } & \multicolumn{4}{c}{ Number of analyzed samples } \\
\cline { 2 - 5 } & South-east Bulgaria & Central north Bulgaria & North-east Bulgaria & The entire country \\
\hline 2007 & 7 & 8 & 10 & 25 \\
2008 & 7 & 5 & 6 & 18 \\
2009 & 5 & 13 & 6 & 24 \\
2010 & 5 & 5 & 6 & 16 \\
2011 & 9 & 13 & 11 & 33 \\
$2007-2011$ & 33 & 44 & 39 & 116 \\
\hline
\end{tabular}

During the period 2007 - 2011, samples (seeds) of the parasite were collected from 116 different locations in the main sunflower production regions (Table 2). The collected seeds were used to infect the genotypes from the differential set. The race composition of broomrape was determined under greenhouse conditions by standard methods (Panchenko, 1973).

Simultaneously with the collecting of seeds from the parasite, observations were made on the percentage of attack in the investigated fields. For this purpose plots of 100 plants each were marked in the crop, observing the rule to mark five evenly positioned plots every 100 da. The index percentage of attack was read reflecting the number of parasitized plants per plot (100 plants). The results were averaged by plots and subsequently for the entire field and investigated area.

\section{RESULTS}

Until 2004 race $\mathrm{E}$ of broomrape had the highest distribution (Shindrova, 2006). This was also confirmed by the results obtained in the first year of this investigation. Race $\mathrm{E}$ was identified in all sunflower production regions of Bulgaria. In southeast Bulgaria it was isolated from $57.1 \%$ of the analyzed samples, and in central north and north-east Bulgaria its percentage in the population was 100 and $90 \%$, respectively (Figures 1-4).

During the period 2005-2006 a more virulent population of the parasite was registered which was identified as race $\mathrm{G}$. At the beginning it occurred in the form of limited areas of primary infection in single sunflower crops in the south-east regions of Bulgaria. The assumption is that race $\mathrm{G}$ penetrated from the territory of Turkey through vehicles, wind, animals, plant residues, etc. It is impressive that this race quickly expands to new territories. The results from this investigation demonstrated that it widened its distribution very fast and in 2007 was isolated from $42.9 \%$ of the samples, although it was still localized only in the region of south-east Bulgaria. In 2007 one sample from north-east Bulgaria was identified as race $\mathrm{H}$ of the parasite. It originated from the border area with Romania (Duranku- 
lak) and was identified for the first time in Bulgaria. This fact confirmed the assumption that the new races in Bulgaria occur in the region of the north Black sea coast where broomrape parasitizes on sea wormwood (Artemisia maritima L.) and later passes over to the sunflower crops (Petrov, 1970). In our later investigations race $\mathrm{H}$ was not isolated from the broomrape population. Our assumption is that in 2007 the race was limited to a single field where sunflower was not grown in the following years.
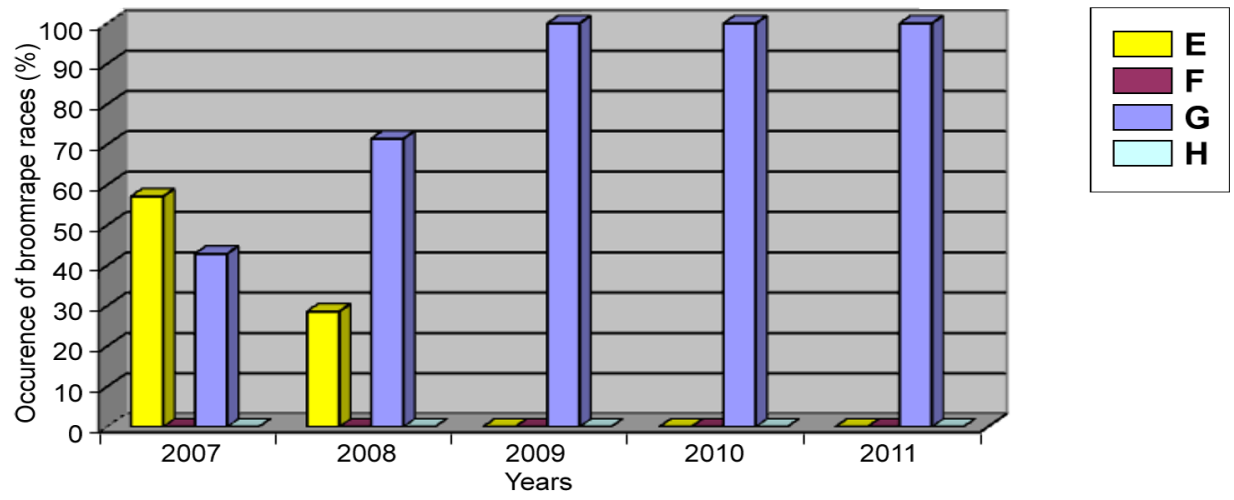

Figure 1: Occurrence of broomrape races in region of south-east Bulgaria (in \%)
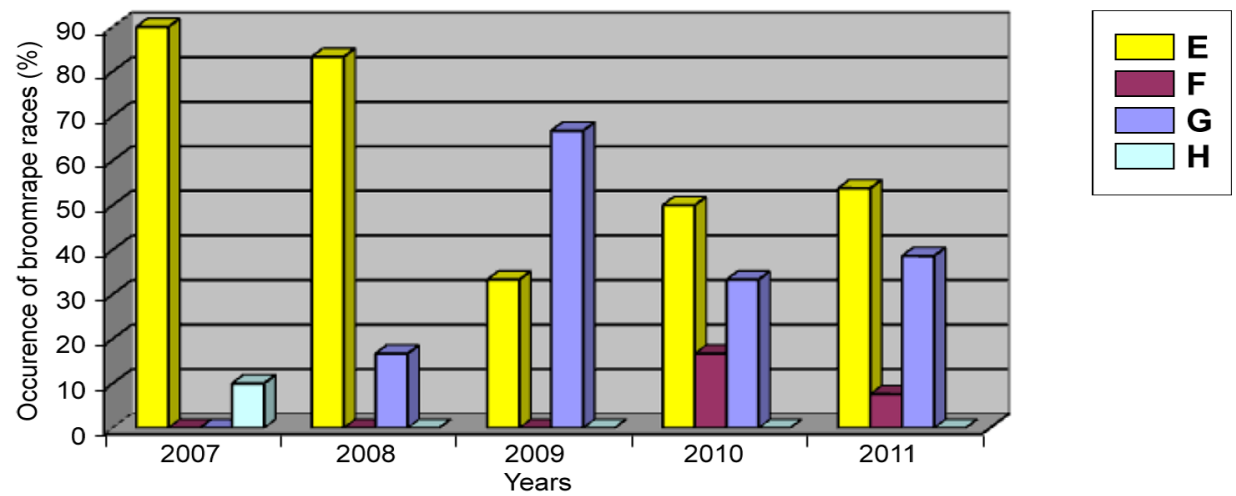

Figure 2: Occurrence of broomrape races in region of north-east Bulgaria (in \%)

According to the results from 2008, race $\mathrm{E}$ was distributed in all regions of Bulgaria but its percentage in the population decreased. This tendency was most clear in the regions of south-east and central north Bulgaria, where the percentage of race E decreased to 28.6 and $40 \%$, respectively. This race was still predominant in north-east Bulgaria where it constituted $83.3 \%$ of the broomrape population. In 2008 race G quickly expanded its area. In the course of a single year it widened its area of distribution in south-east Bulgaria to $71.4 \%$ of the population. The race was already identified also in central north and north-east Bulgaria. It was isolated from 
40 and $16.7 \%$ of the samples with origin from these regions. In 2008 the broomrape population included also race $\mathrm{F}$, but its occurrence was sporadic, most probably due to the fast changing varietal structure and the strong breeding pressure on the parasite.
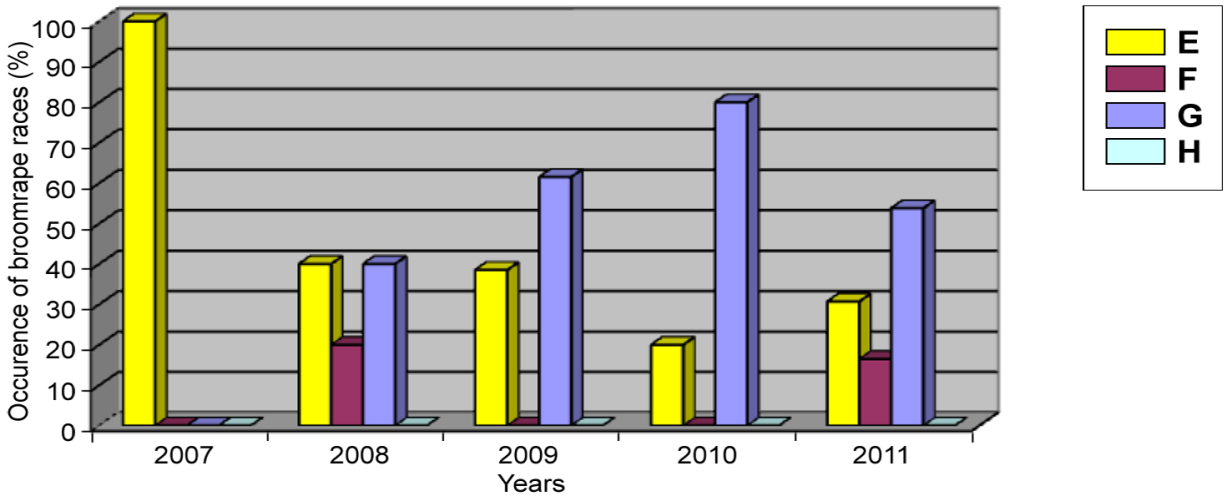

Figure 3: Occurrence of broomrape races in region of central-north Bulgaria (in \%)
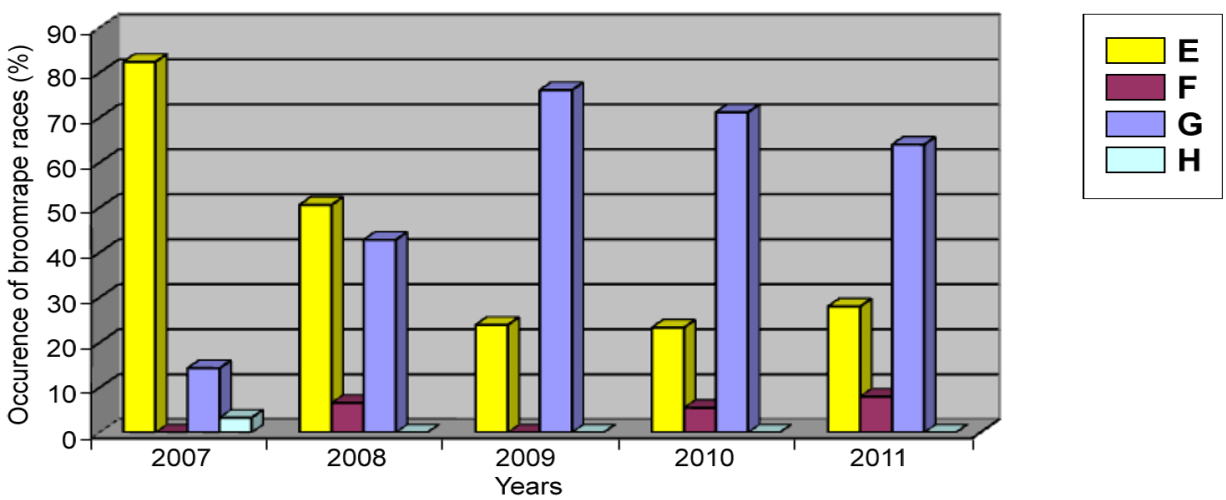

Figure 4: Occurrence of broomrape (in \%) - average values for all observed Bulgarian regions

In 2009 and 2010 two races were predominant in the broomrape population: races $\mathrm{E}$ and $\mathrm{G}$. Race $\mathrm{E}$ gradually decreased its percentage. It was not identified in the samples from the region of south-east Bulgaria. The opposite tendency was observed in race $\mathrm{G}$, which constituted $100 \%$ of the parasite's population in this region. Similar regularity was outlined in central north Bulgaria too, where race $\mathrm{E}$ decreased its percentage to 38.5 and $20 \%$, respectively, and the percentage of race G reached $61.5 \%$ in 2009 and $80 \%$ in 2010 . The distribution of race G increased in north-east Bulgaria as well, from $16.7 \%$ in 2008 to $66.7 \%$ in 2009 . The tendency in race $\mathrm{E}$ was the opposite: from $83.3 \%$ its percentage decreased to $33.3 \%$ in 2009 . Besides these two races, race $\mathrm{F}$ was also isolated in the region of north-east Bulgaria in 2010 , constituting $16.7 \%$ of the population. 
The results from the last year of the investigation showed that race G was completely dominant in the region of south-east Bulgaria and was isolated from $100 \%$ of the samples. It was also predominant in the populations from central north Bulgaria $-53.8 \%$. Races $\mathrm{E}$ and $\mathrm{F}$ were identified in this region, constituting 30.7 and $16.5 \%$ of the local populations, respectively. The three races were also isolated from the samples with origin from north-east Bulgaria, but in this region race $\mathrm{E}$ was still predominant with $53.8 \%$.

The data reflecting the percentage of attack varied by region and by year (Figure 5). Averaged for the period of investigation, the percentage was lowest in 2007 and this tendency was valid for all regions. This may be related to the fact that during this period race $\mathrm{E}$ had the highest distribution, and the sunflower genotypes predominantly used in production were resistant to this race. In the following years the percentage of attack increased in all regions, but mostly in south-east and northeast Bulgaria, where this index exceeded 50\%. Undoubtedly, this process is related to the expanding area of distribution of race $\mathrm{G}$.

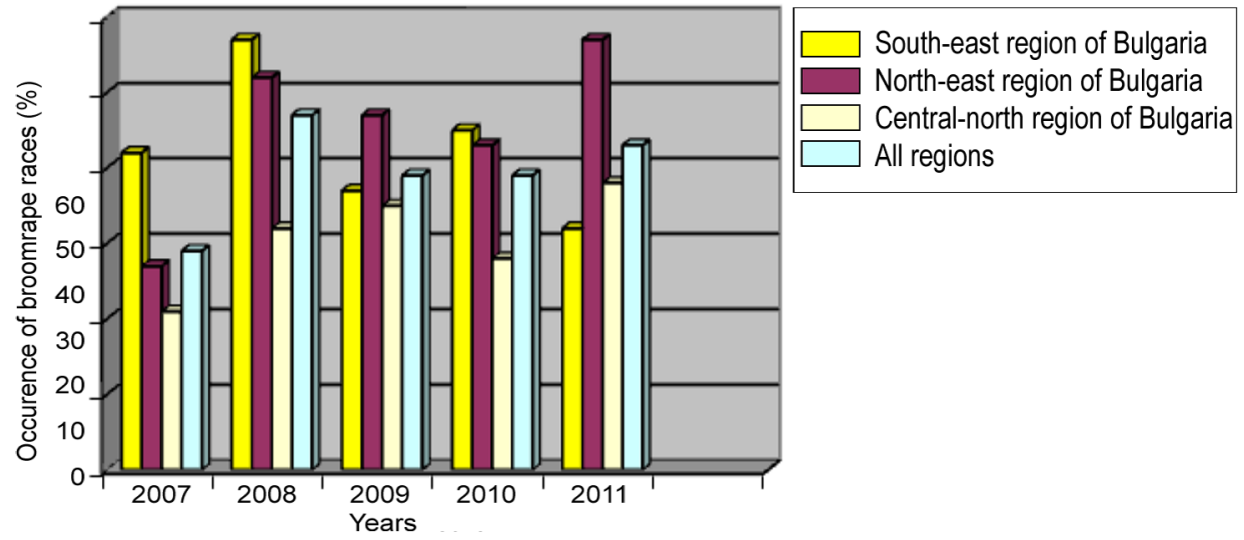

Figure 5: Highest percent of broomrape attack in the investigated fields

\section{CONCLUSIONS}

The broomrape population in Bulgaria includes 4 races: $\mathrm{E}, \mathrm{F}, \mathrm{G}$ and $\mathrm{H}$. Races $\mathrm{E}$ and $\mathrm{G}$ have the highest distribution. During the years of investigation race $\mathrm{E}$ gradually decreased its percentage in the population but was still predominant in northeast Bulgaria, while its percentage was equal to race $\mathrm{G}$ in central north Bulgaria. The broomrape population in south-east Bulgaria was constituted entirely of race $\mathrm{G}$, which will probably continue to increase its percentage in the upcoming years to other regions of the country as well. Race $\mathrm{F}$ is of sporadic occurrence. It was isolated in single years, had limited distribution and there is no danger of its mass occurrence. The population identified as race $\mathrm{H}$ was isolated only in 2007. It can be assumed that this is a "primary source of infection" that will expand from now on; for the time being, however, it is localized on a very small area. 


\section{REFERENCES}

Dobrev, H., 1945. Sunflower broomrape. Semeproizvodstvo 3: 99-103.

Encheva, V., Shindrova, P., 1994. Broomrape (Orobanche cumana Wallr.) - a problem of sunflower production in Bulgaria. Proceedings of the Third International Workshop on Orobanche and related Striga research, Amsterdam, pp. 619-622.

Pancenko, A.N., 1973. Rannija diagnostika zarazihoustoicivosti ori selekcii podsolnecnika. Zbirnik VNIIMK, pp. 107-115.

Petrov, D., 1970. A new physiological race of broomrape in Bulgaria (Orobanche cumana Wallr.). Zashtita v pomosht na selskoto stopanstvo, Sofia, pp. 37-47.

Shindrova, P., 2004. Distribution and race composition of Orobanche cumana Wallr. in Bulgaria. Proceedings of the Third International Workshop on Orobanche and related Striga research, Amsterdam, pp. 142 - 145.

Shindrova, P., 2006. Broomrape (Orobanche cumana Wallr.) in Bulgaria - Distribution and race composition. Helia 29(44): 111-120. 
